\title{
Elevated circulating somatostatin levels in acromegaly
}

\author{
M. Arosio*,***, S. Porretti*, P. Epaminonda**,***, C. Giavoli*, C. Gebbia**, \\ C. Penati**, P. Beck-Peccoz*, and M. Peracchi** \\ *Institute of Endocrine Sciences, **Department of Medical Sciences, University of Milan, Ospedale \\ Maggiore IRCCS, ${ }^{\star \star \star}$ Ospedale S. Giuseppe, A.Fa.R., Milan, Italy
}

\begin{abstract}
GH increases hypothalamic somatostatin (SS) synthesis and secretion but it is unknown if chronic GH excess, as found in acromegaly, may influence circulating SS levels, that are mainly of enteropancreatic source and affect several gastrointestinal functions, including motility. Circulating SS occurs in several post-translational forms including somatostatin-14 (SS-14), somatostatin28 (SS-28) and other small peptides. The aim of the present study was to characterize the fasting and postprandial pattern of plasma circulating somatostatin in normal subjects and patients with acromegaly. Fasting total SS and SS-28 levels were measured in 32 subjects, 16 acromegalic patients with a new diagnosis (A) (8 F, $8 \mathrm{M}$, median age 48) and 16 matched healthy volunteers $(C)(8 F, 8 \mathrm{M}$, median age 45). SS was also determined after a standard solid-liquid meal $(550 \mathrm{kCal})$ in 24 of the subjects (12 C and $12 \mathrm{~A}$ ). Fasting SS and SS-28
\end{abstract}

\section{INTRODUCTION}

$\mathrm{GH}$ and somatostatin are closely connected hormones. Somatostatin (SS) is the mainly inhibitory regulator of pituitary $\mathrm{GH}$ secretion, whereas $\mathrm{GH}$ increases hypothalamic SS synthesis and secretion either directly, by a short feed-back mechanism, or indirectly, via IGF-I (1). However, SS is synthesized and secreted by many tissues other than the hypothalamus. In particular, it is produced in the $\delta$ cells of the gastrointestinal tract and pancreas and several data indicate that these tissues are the main source of circulating SS (2). It is still unknown if persistent chronic $\mathrm{GH}$ excess, as found in acromegaly, may alter circulating SS levels. SS in-

\section{${ }^{\circ} 2003$, Editrice Kurtis}

Key-words: Somatostatin/blood, somatostatin isoforms, acromegaly.

Correspondence: M. Arosio, M.D., Istituto di Scienze Endocrine, Ospedale San Giuseppe, Via S. Vittore 12, I-20123 Milano, Italy.

E-mail:maura.arosio@unimi.it

Accepted November 28, 2002. were significantly higher in acromegalic patients as compared to healthy subjects. In the former, a positive correlation was found between IGF-I and SS levels $(r=0.525 p<0.05)$. Furthermore, the ratio between SS (as pmol equivalent SS-14/I) and SS-28 was higher in the acromegalic patients than in the controls $(3.4 \pm 2.1$ vs $2.0 \pm 1.6, p<0.05)$. The postprandial SS peak, as well as the incremental area above baseline values, was similar in the patients and controls. In conclusion, fasting but not postprandial hypersomatostatinemia, mainly due to an increase in SS-14, characterizes acromegaly. Excess GH/IGF-I could be a causal factor in somatostatin hypersecretion. Conceivably this abnormality might play a role in some alterations of gastrointestinal function of acromegalic patients such as prolonged bowel transit.

(J. Endocrinol. Invest. 26: 499-502, 2003)

${ }^{\odot}$ 2003, Editrice Kurtis

hibits various gastrointestinal functions including motility (3), and modifications in its levels could explain some of the alterations in gastrointestinal functions found in untreated acromegalic patients, such as prolonged bowel transit (4) and impaired gall bladder emptying (5).

SS is synthesized as a prohormone which undergoes tissue-specific processing to produce either a tetradecapeptide, somatostatin-14 (SS-14), or an $\mathrm{N}$-terminally extended form of 28 amino acids, somatostatin-28 (SS-28). Both forms are present in the circulation, and their biological significance has still to be determined in detail (2). SS immunoreactivity is due also to other post-secretory conversion products such as SS-13 and SS-25. Food ingestion increases SS plasma levels, mainly of the SS-28 form, and a standardized mixed meal is a good and reproducible stimulus for SS release in the circulation $(6,7)$.

The aim of this study was to characterize the fasting and postprandial pattern of plasma SS in a series of normal subjects and in patients with active acromegaly. 


\section{PATIENTS AND METHODS}

\section{Subjects}

Sixteen acromegalic patients, all with a new diagnosis $(8 \mathrm{~F}, 8 \mathrm{M}$, aged $26-65$ years, median 48 ) and 16 healthy subjects $(8 \mathrm{~F}, 8 \mathrm{M}$, aged $25-65$ years, median 45$)$, recruited from medical staff and acquaintances of patients, volunteered for this study, which was approved by the local ethics committee. Healthy subjects had normal physical examination and no history of gastrointestinal or endocrine disorders, and were not taking any medication. Acromegalic patients had the characteristic clinical features of the disease, elevated age-adjusted serum IGF-I concentrations [mean 93 \pm 42.0 (SD) nmol/l, range 43-186], elevated serum $\mathrm{GH}$ levels (mean 10 $\pm 9.6 \mu \mathrm{g} / \mathrm{l}$, range 2.1-37.6) that were not suppressible to less than $1 \mu \mathrm{g} / \mathrm{l}$ during a $75 \mathrm{~g}$ oral glucose tolerance test, and an adenoma at pituitary imaging. No patients had diabetes mellitus but 9 of them showed impaired glucose tolerance according to the American Diabetes Association criteria (8). No patient had anterior pituitary hormone deficiencies.

\section{Procedures}

In all subjects 2 blood samples were taken 30 min apart after an overnight fast, for GH, SS, SS-28 and IGF-I assays. In addition, 12 acromegalic patients, and 12 matched healthy subjects received a mixed standardized solid-liquid meal (550 kcal: $48 \%$ carbohydrate, $33 \%$ fat, $19 \%$ protein) given at 0 time and eaten in $15 \mathrm{~min}$. Blood was taken at $-30,0,15,30,45,60,90,120,150$ and 180 $\mathrm{min}$. Insulin and glucose concentrations were measured in addition to $\mathrm{SS}$ in all these samples. Samples were collected in plain tubes for GH, IGF-I and insulin assays, and in ice-chilled polypropylene tubes containing EDTA (1 mg/ml) and aprotinin (500 klU/ml) for SS assays. Plasma was immediately separated by centrifugation at 4 $\mathrm{C}$ whereas the serum was separated within 1-3 h; both plasma and serum were stored in aliquots at $-80 \mathrm{C}$ until assayed.

\section{Assays}

Both SS and SS-28 levels were measured after extraction on SepPak $\mathrm{C}_{18}$ cartridges, as previously described (9) using commercially available RIA kits (Peninsula Laboratories Inc., Belmont, CA, USA). SS levels were assayed in all the samples. The antiserum employed had $100 \%$ cross-reactivity with SS-14 and SS28 , and synthetic SS-14 was used as standard. Results were expressed as pmol equivalent SS-14/I. The 95\% confidence detection limit was $1.5 \mathrm{fmol} /$ tube and the intra- and interassay coefficients of variation (CV) were 7.9 and $9.6 \%$, respectively. The mean recovery of synthetic SS-14 (50 and $100 \mathrm{pg}$ ) added to plasma before the extraction was $81 \%$.

SS-28 levels were measured in fasting conditions only. The assay was performed using a specific antiserum for SS-28 that does not recognize SS-14, with synthetic SS-28 as standard. The $95 \%$ confidence detection limit was $1.0 \mathrm{fmol} /$ tube and the intraand interassay $\mathrm{CV}$ were 5.6 and $8.4 \%$, respectively. The mean recovery of synthetic SS-28 (50 and $100 \mathrm{pg}$ ) added to plasma before the extraction was $79 \%$.

Serum IGF-I and GH levels were measured by commercially available kits (IGF-I: Mediagnost, Tubingen, Germany; GH: AutoDelfia ${ }^{\circledR}$ hGH, EG\&G Wallac, Finland).

Insulin concentration was measured by an immunoenzymetric one-step assay (Medgenix-Ins-Easia, Belgium) with a sensitivity of $0.15 \mathrm{mU} / \mathrm{l}$, and plasma glucose levels by a hexokinase method (Beckman, Milano, Italy).

\section{Statistical analyses}

Data were expressed as mean $\pm S D$, unless otherwise stated. The integrated areas of secretion (AUC) were calculated with the trapezoidal method. All data were first tested for normality of distribution by the Kolmogoroff-Smirnoff test. If necessary, logarithmic transformations were done to approach normal distribution. Variables were compared by paired and unpaired Student's t-test, as appropriate.

The correlation between the different parameters was carried out by Pearson's correlation coefficient. A $p<0.05$ was considered statistically significant.

\section{RESULTS}

\section{Fasting somatostatin levels}

The results are summarized in Table 1 and Figure 1. There were no age- or sex-related differences in the two groups of subjects. In the patients with acromegaly both SS and SS-28 fasting levels were significantly higher than those of the healthy subjects (Table 1). Moreover, the SS/SS-28 ratio was significantly higher in the former $(3.4 \pm 2.1 \mathrm{vs}$ $2.0 \pm 1.6, p<0.05)$, suggesting that SS-14 was increased more than SS-28 in the acromegalic patients. Fasting SS levels were clearly elevated in 12 of the 16 acromegalic patients (observed range: 9.1-28.7 pmol/l), whereas in the other 4 they were similar to those found in healthy subjects (Fig. 1). Considering all patients, IGF-I levels correlated positively with SS (but not SS-28) concentrations $(r=0.525, p<0.05)$ (Fig. 2).

\section{Response to the meal}

Plasma SS response to the standard meal, evaluated as total AUC, was significantly higher in the patients with acromegaly than in the healthy subjects. However, the postprandial SS peak, as well as the incremental area above baseline, was similar in the healthy subjects and in the patients (Table 1). The

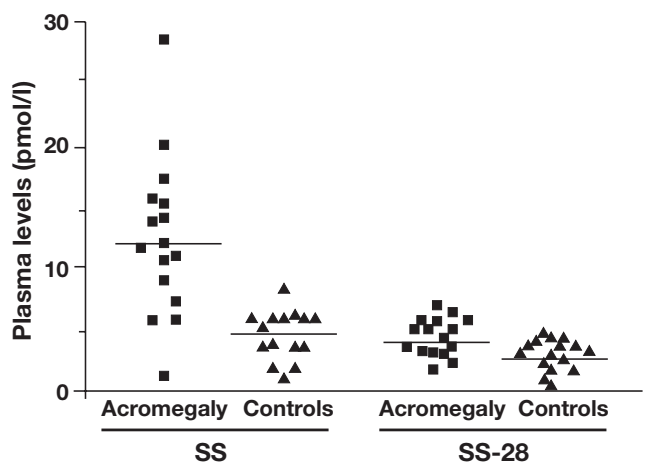

Fig. 1 - Fasting total plasma somatostatin (SS) and somatostatin28 (SS-28) levels in 16 acromegalic patients and 16 sex- and age-matched healthy subjects. 
Table 1 - Pattern of fasting and postprandial somatostatin levels. Data are expressed as mean \pm SD.

\begin{tabular}{|c|c|c|c|c|c|}
\hline & No. & $\begin{array}{l}\text { Healthy } \\
\text { subjects }\end{array}$ & No. & $\begin{array}{l}\text { Acromegalic } \\
\text { patients }\end{array}$ & $p$ value \\
\hline \multicolumn{6}{|l|}{ Somatostatin (SS) } \\
\hline Fasting $(\mathrm{pmol} / \mathrm{l})^{\star}$ & 16 & $4.78 \pm 1.98$ & 16 & $12.5 \pm 6.5$ & 0.0001 \\
\hline Meal & 12 & & 12 & & \\
\hline Basal (pmol/l)* & & $4.5 \pm 1.8$ & & $10.1 \pm 4.5$ & $<0.001$ \\
\hline Peak (pmol/l)* & & $15.8 \pm 4.0$ & & $17.7 \pm 7.3$ & NS \\
\hline AUC (pmol////3h)* & & $1671 \pm 315$ & & $2139 \pm 1177$ & $<0.05$ \\
\hline Net-AUC (pmol////3h)* & & $777 \pm 474$ & & $604 \pm 275$ & NS \\
\hline \multicolumn{6}{|l|}{ Somatostatin 28 (SS-28) } \\
\hline Fasting $(\mathrm{pmol} / \mathrm{l})$ & 16 & $2.8 \pm 1.21$ & 16 & $4.1 \pm 1.3$ & $<0.01$ \\
\hline SS/SS-28 & 16 & $2.0 \pm 1.6$ & 16 & $3.4 \pm 2.1$ & $<0.05$ \\
\hline
\end{tabular}

${ }^{*}$ As pmol equivalent SS-14.

time course of the SS response after the meal did not differ between patients and healthy subjects (Fig. 3). Glucose and insulin levels rose significantly after the meal in both acromegalic patients (insulin from $22 \pm 8$ to $149 \pm 103 \mathrm{mU} / \mathrm{l}, p<0.001$; glucose from $5.1 \pm 0.4$ to $7.2 \pm 0.8 \mathrm{mmol} / \mathrm{l}, p<0.05)$ and healthy subjects (insulin from $12 \pm 4$ to $40 \pm 16 \mathrm{mU} / \mathrm{l}$ $p<0.001$; glucose from $4.6 \pm 0.3$ to $5.8 \pm 0.5 \mathrm{mmol} / \mathrm{l}$ $p<0.05)$. As expected, acromegalic patients had significantly higher fasting and postprandial insulin $(p<0.001)$ and glucose levels $(p=0.01)$.

\section{DISCUSSION}

This study indicates that acromegalic patients tend to have higher fasting SS levels than healthy subjects, whereas the SS response to a standard meal appears similar in both groups. Elevated fasting levels were found in two assays, one that recognizes both SS-14 and SS-28 and one that recognizes only SS-28. However, the finding of a significantly higher SS/SS28 ratio in acromegalic patients than in controls suggests that in acromegaly SS-14 is increased more

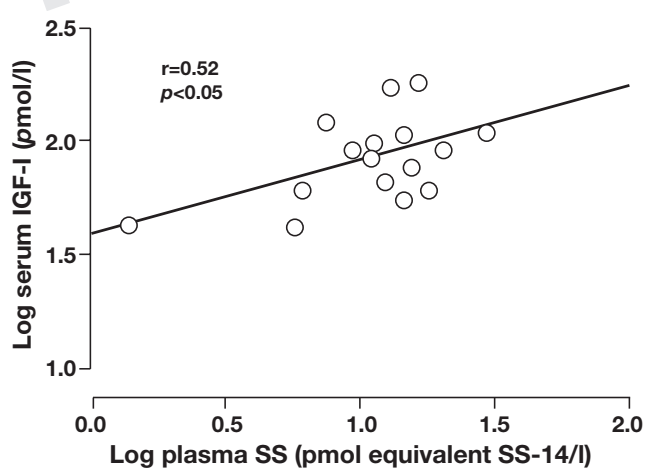

Fig. 2 - Correlation between fasting circulating levels of total somatostatin (SS) and IGF-I in 16 acromegalic patients. than SS-28, the predominant released form from the small intestine in healthy subjects.

To our knowledge only one previous study has considered SS levels in acromegaly (10). The Authors found mean concentrations slightly, but not significantly, higher than those of a group of healthy controls, with a subgroup of acromegalic patients showing clearly elevated SS levels, in agreement with the present results. Differences in number of patients, type of assay and specificity of the antibody used may in part explain the discrepancy between their results and ours.

The significant correlation between SS and IGF-I concentrations found in our acromegalic patients suggests a direct relation between elevated circulating SS levels and prolonged exposure to high $\mathrm{GH}$ and IGF-I levels. It is well documented by in vitro and in vivo studies that $\mathrm{GH}$ induces the synthesis and release of hypothalamic SS. In fact, intact GH-treated rats have higher levels of pre-prosomatostatin mRNA in the periventricular nucleus (PeVN) of the hypothalamus than control rats. Moreover, dwarf mutant mice

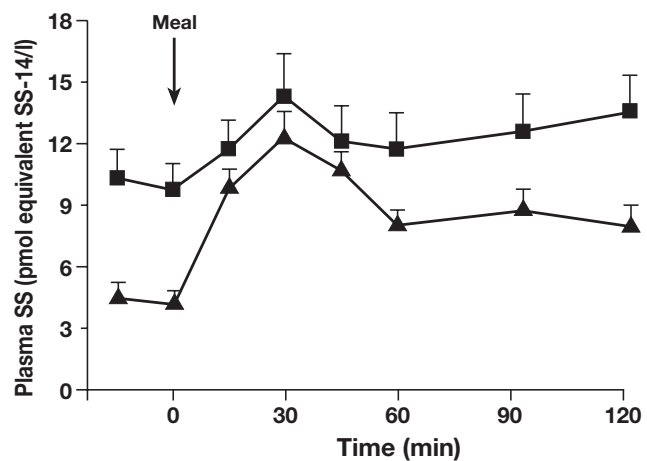

Fig. 3 - Pattern of plasma total somatostatin (SS) after a standard meal in 12 acromegalic patients (squares) and 12 healthy subjects (triangles) (mean \pm SE). 
lacking $\mathrm{GH}$ have a selected depletion of somatostatin mRNA in the PeVN (1), and SS expression is markedly increased in mice transgenic for $\mathrm{GH}$ (11). Although all these data refer to hypothalamic SS, it is tempting to speculate that $\mathrm{GH}$ might also induce the synthesis and release of SS of gastro-entero-pancreatic origin. The finding that plasma SS levels increased after 3 months of treatment with $\mathrm{GH}$-releasing hormone in non GH-deficient children (12) is in keeping with this hypothesis. Nevertheless, other mechanisms could contribute to the modifications of fasting SS levels in acromegaly. For example, it has been shown that gastric inhibitory polypeptide (GIP) stimulates the release of circulating SS (13), and acromegalic patients have been observed to have both fasting and postprandial GIP levels higher than healthy subjects (14). Elevated circulating concentrations of SS have been described to occur in other endocrine diseases such as hypothyroidism (15), and insulin-deficient Type 1 diabetes at diagnosis (16), but, in the present study, all the patients had thyroid free hormones levels, fasting glucose levels and glycated hemoglobin in the normal range. Only an impaired glucose response to the glucose load (IGT) was present in 9 patients, but no difference in SS and SS-28 concentrations was observed between patients with normal or impaired glucose tolerance. Thus the alterations in glucose metabolic control that characterize acromegaly do not seem to play a causal role in increasing circulating SS levels, all the more that patients with Type 2 diabetes mellitus and IGT have been described to have normal SS levels (16-18) and even reduced, and not increased, fasting SS-28 concentrations (18).

In conclusion, we have found that most acromegalic patients have elevated fasting SS levels. The rise is mainly due to an increase of SS-14 in respect to SS28. In keeping with this finding the SS peak reached after a meal is similar to that observed in normal subjects. Excess GH/IGF-I could be a causal factor.

\section{ACKNOWLEDGMENTS}

The Authors are indebted to Prof. Giovanni Faglia for stimulating discussions, and are grateful to Simona Pizzinelli for expert technical assistance. The present study was partially supported by research grants from FIRST fund of the University of Milan and from "Associazione amici della gastroenterologia del Padiglione Granelli", Milan. It was presented in part at the XXVII National Congress of the Italian Society of Endocrinology, Torino, 1999.

\section{REFERENCES}

1. Müller E.E., Locatelli V., Cocchi D. Neuroendocrine control of growth hormone secretion. Phys. Rev. 1999, 79: 511-607.

2. Beglinger C., Drewe J. Somatostatin and octreotide: physiological background and pharmacological application. Digestion 1999, 60: 2-8.
3. Peracchi M., Basilisco G., Bareggi B., Cavagnini F., Quattrini M., Velio P., Bianchi, P.A. Plasma somatostatin levels in patients with chronic idiopathic intestinal pseudoobstruction. Am. J. Gastroenterol. 1997, 92: 1884-1886.

4. Veysey M.J., Thomas L.A., Mallet A.I., et al. Prolonged large bowel transit increases serum deoxycholic acid: a risk factor for octreotide induced gallstones. Gut 1999, 44: 675-681.

5. Catnach S.M., Anderson J.W., Fairclough P.D., et al. Effect of octreotide on gall stone prevalence and gall bladder motility in acromegaly. Gut 1993, 34: 270-273.

6. Wass J.A.H., Penman E., Dryburgh J.R., et al. Circulating somatostatin after food and glucose in man. Clin. Endocrinol. (Oxf.) 1980, 12: 569-574.

7. Ensinck J.W., Laschansky E.C., Vogel R.E., Simonowitz D.A., Roos B.A., Francis B.H. Circulating prosomatostatinderived peptides. Differential responses to food ingestion. J. Clin. Invest. 1989, 83: 1580.

8. The Expert committee on the diagnosis and classification of the diabetes mellitus. Committee Report. Diabetes Care 1997, 20: 1183-1197.

9. Peracchi M., Carola F., Cavagnini F., et al. Plasma somatostatin-like immunoreactivity and somatostatin-28 levels in obese men. J. Endocrinol. Invest. 1998, 21: 20-23.

10. Wass J.A.H., Penman E., Medbak S., Rees L.H., Besser G.M. CSF and plasma somatostatin levels in acromegaly. Clin. Endocrinol. (Oxf.) 1980, 13: 235-241.

11. Hurley D.L., Bartke A., Wagner T.E., Wee B.E., Phelps C.J. Increased hypothalamic somatostatin expression in mice transgenic for bovine or human GH. J. Neuroendocrinol. 1994, 6: 539-548.

12. Arilla E., Fragoso J., Barrio R., et al. Plasma somatostatinlike immunoreactivity during growth-hormone-releasing hormone therapy in non-growth-hormone-deficient children. Horm. Res. 1990, 34: 71-74.

13. Ahren B., Patterson M., Uvnas-Moberg K., Gutniak M., Efendic S. Effects of cholecystokinin (CCK)-8, CCK-33, and gastric inhibitory polypeptide (GIP) on basal and mealstimulated pancreatic hormone secretion in man. Diabetes Res. Clin. Pract. 1991, 13: 153-161.

14. Peracchi M., Porretti S., Gebbia C., et al. Increased glucose-dependent insulinotropic polypeptide (GIP) secretion in acromegaly. Eur. J. Endocrinol. 2001, 145, R1-R4.

15. Kung A.W., Lam K.S., Pun K.K., Wang C., Yeung R.T. Circulating somatostatin after oral glucose in hypothyroidism. J. Endocrinol. Invest. 1990, 13: 403-406.

16. Segers O., De Vroede M., Micotte Y., Somers G. Basal and tolbutamide-induced plasma somatostatin in healthy subjects and in patients with diabetes and impaired glucose tolerance. Diabetic. Med. 1989, 6: 232-238.

17. Conlon J.M., McCulloch A.J., Alberti K.G. Circulating somatostatin concentrations in healthy and non-insulin-dependent (type II) diabetic subjects. Diabetes 1983, 32:723-729.

18. D'Alessio D.A., Ensinck J.W. Fasting and postprandial concentrations of somatostatin-28 and somatostatin-14 in type II diabetes in men. Diabetes 1990, 39: 1198-1202. 